\title{
Discharge Measurements in Open Channels using Compound Sharp-Crested Weirs
}

\author{
M. Piratheepan, N.E.F. Winston and K.P.P. Pathirana
}

\begin{abstract}
Compound sharp-crested weirs have been widely used for measuring discharges in open channels accurately with a reasonable sensitivity over a wide flow range. The flow characteristic over a compound sharp-crested weir is completely different to that over a single sharp-crested weir. The most common type of compound sharp-crested weir used in irrigation canals is the combination of a rectangular notch and a ' $\mathrm{V}$ ' notch with a small notch angle. However, the continuity of flow and precision of this type of compound weirs are reported to be poor in the transition region between two sections. As an improvement, a compound sharp-crested weir composed of two triangular parts with different notch angles has been designed and experimentally validated which proved to be accurate in measuring a wide range of discharges without any discontinuity. Several methods are also proposed to estimate the flow over the double ' $\mathrm{V}$ ' notch compound sharp-crested weir and one method is experimentally validated as most suitable.
\end{abstract}

Keywords: Compound sharp-crested weir, Discharge coefficient, Steady uniform flow

\section{Introduction}

Accurate flow measurement in open channels is very important in many civil engineering applications. There are different types of structures available for flow measurements such as weirs, orifice, flumes, sluice gates etc. The structures used for flow measurements should he accurate, economical and easy to use (installation, operation and maintenance). Weirs allow water to be routed through a structure of known dimensions, permitting flow rates to be measured as a function of depth of flow through the structure. Among different types of weirs, a sharp-crested weir has been widely used for discharge measurements in open channels. The commonly used cross sections of sharp-crested weirs are rectangular, trapezoidal and triangular. A triangular weir with a small notch angle is found to be accurate in discharge measurements; however, it can only be used to measure small discharges. When measuring high discharges by using the single sharpcrested weirs, backwater effects might affect the structures located upstream of the weir.

When the discharge is to be measured accurately with a reasonable sensitivity over a wide range of flows, the use of compound sharp-crested weirs could be an appropriate solution. The most commonly used compound sharp-crested weirs used in irrigation canals have a combination of rectangular notch and a
' $V$ ' notch with a small notch angle. But it has been already found that the accuracy of flow measurements of this type of structure is poor in the transition region between the two parts. Therefore, in order to overcome this problem and also to measure flow rates accurately for a wide range of discharges, the use of a compound sharp-crested weir having a combination of two triangular weirs with different notch angles has been studied. This paper presents the details of the experimental investigations conducted with a compound sharp-crested weir having two triangular ' $\mathrm{V}$ ' notches with different notch angles for estimating discharge accurately over a wide range of flows.

\section{Literature Review}

Many studies have been carried out in the past to investigate the discharge over sharp-crested weirs with fully and partially developed flows. Henderson [8] presented an elementary analysis for discharge over a sharp-crested weir by assuming that the flow does not contract as it passes over the weir. By assuming that the pressure across the whole water column over

M.Piratheepan, B.Sc. Eng. (Hons),Department of Civil Engineering, University of Peradeniya.

N.E.F.Winston, B.Sc. Eng. (Hons), Department ofCivil Engineering, University of Peradeniya.

Eng.(Dr.) K.P.P. Pathirana, B.Sc. Eng. (Hons.) (Peradeniya), M.Eng., Ph.D., C.Eng., FIE(SL), MICE (London), Senior Lecturer, Department of Civil Engineering, University of Peradeniya. 
the weir is atmospheric the following equation was derived for discharge as,

$Q=\frac{8}{15} C_{c d} \tan \left[\frac{g}{2}\right] \sqrt{2 \mathrm{~g}} h^{2.5}$

Where, $Q=$ discharge; $C=$ discharge coefficient; $g=$ gravitational acceleration; $6=$ notch angle; and $h=$ head over the weir.

Some of the researchers adjust the head over the weir to eliminate the effects of lateral and vertical contractions with the limitation of applicability (Bos [4], Brater et al. [5], Kindswater et al. [9] and Chow [7]). Later a correction factor $(K)$ has been introduced to the head over the weir by considering the surface tension and viscous effects (USBR [13]). The discharge coefficient solely depends on the notch angle for fully developed flow and depends on many other parameters for partially developed flow. It is recommended in BSI [6] that the head over the weir need to be adjusted for both partially and fully contracted flows. As all the references show similar curves for $C_{d^{\prime}}$ and $K$ without providing the equations for them, LMNO Engineering [12] used a curve fitting program to obtain the following relationships for $C_{d}$ and $K$, both of which are related to notch angle of weir,

$C_{d}=0.6072-0.000874 \theta+6.1 \times 10^{-6} \theta^{2}$

$K=4.42-0.1035 \theta+1.005 \times 10^{-3} \theta^{2}-3.24 \times 10^{-6} \theta^{3}$

Where, $\theta$ is the notch angle. The specifications and the proper installation of weirs for flow measurements in both partially and fully contracted flow conditions are clearly discussed in BSI and USBR [13].

Very few studies are reported in the past on compound sharp-crested weirs with the aim of improving the performance of single sharpcrested weir. Abdel-Azim et al. [1] discussed the characteristics of the combined flow over weirs and below gates of equal contraction for the purpose of avoiding the problem of sediment accumulation upstream from the weir. On the other hand, the characteristics of a compound weir consisting of a rectangular notch with a Vnotch cut into the centre of the crest are discussed in the USBR [13], and this could handle the normal range of discharges by lower
$\mathrm{V}$-notch and the occasionally occurring larger flows by the rectangular weir. However, the discontinuity in the discharge curve has been a major problem in the above stated combination of notches when measuring discharge in the transition range. To avoid this problem Martinez et al. [10] proposed a compound sharp-crested weir which has two triangular weirs with different notch angles. They proposed and validated a theoretical discharge equation for fully contracted flow condition by conducting the experiment with different combinations of notch angles.

In this paper various methods of estimating discharge over the compound sharp-crested weir, having a combination of two triangular weirs in partially contracted flow conditions are compared based on the experimental investigations. The most suitable method of computing discharge over the compound weir is proposed. The accuracy and continuity of discharge measurements using this type of compound weirs are also discussed.

\section{Theoretical Aspects}

A weir is considered to be a sharp-crested weir, when the crest thickness is between $1 \mathrm{~mm}$ and 2 $\mathrm{mm}$. when the thickness exceeds the specified limits, it is required to be bevelled to at least 600 for triangular weirs and at least 450 for rectangular weirs. The bevelled section should be faced towards the downstream. The tail water level should be low enough to ensure the free fall of the nappe.

The discharge equation for the sharp-crested weir is obtained by integrating the flow through a small elemental strip over the nappe at the weir; where each flow strip, is considered with a different head. The discharge equation for a typical triangular weir is given in Eq.(1). The discharge over the compound weir with two triangular weir sections is calculated by adding the flow through the triangular areas $1 \& 2$ and subtracting the flow through the intersected triangular area as shown in Figure-1. The $\mathrm{Cd}$ values for the lower ' $V$ ' notch and the upper ' $V$ ' notch are calculated separately and used to predict the flow. Eq.1 can be used to predict the flow over the weir when head over the weir (h) is less than the lower weir height $(\mathrm{hO})$ and in this case, the discharge coefficient corresponding to the lower ' $V$ ' notch is used. When the head over 
the weir is greater than $h_{\alpha}$ six different methods are proposed to estimate the flow over the compound weirs, which are presented in detail in the following sections.

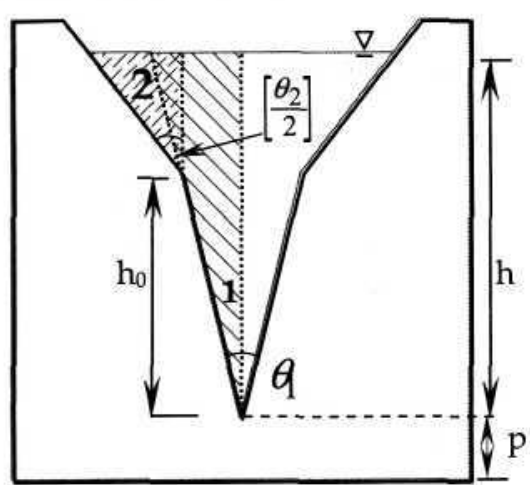

(a)

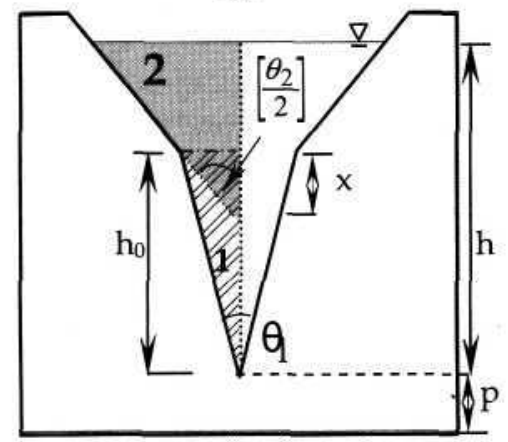

(b)

Figure 1- Typical cross section of the compound sharp-crested-weirs $(a \& b)$

\section{Method -1}

F lere, the intersection triangle is in the upper ' $\mathrm{V}$ ' notch and hence, the $C_{d}$ corresponding to this area is taken as the lower ' $\mathrm{V}$ ' notch discharge coefficient.

$$
\begin{aligned}
Q= & \frac{8}{15} C_{d_{2}} \sqrt{2 g} \tan \left[\frac{\theta_{2}}{2}\right]\left(h-h_{0}\right)^{2.5} \\
& +\frac{8}{15} C_{d_{1}} \sqrt{2 g} \tan \left[\frac{\theta_{1}}{2}\right] h^{2.5} \\
& -\frac{8}{15} C_{d_{1}} \sqrt{2 g} \tan \left[\frac{\theta_{1}}{2}\right]\left(h-h_{0}\right)^{2.5}
\end{aligned}
$$

Where $C_{d}=$ discharge coefficient of the lower ${ }^{\prime} \mathrm{V}^{\prime}$ notch, $C_{d 2}=$ discharge coefficient of the upper ' $\mathrm{V}^{\prime}$ notch, $\theta_{1}=$ lower notch angle and $\theta_{2}=$ upper notch angle.

\section{Method-2}

Here, the intersection triangle is in the lower ' $\mathrm{V}$ ' notch and hence, the $C_{d}$ corresponding to this area is taken as the upper ' $\mathrm{V}$ ' notch discharge coefficient (see Figure 1 (b)).

$$
\begin{aligned}
Q= & \frac{8}{15} C_{d_{2}} \sqrt{2 g} \tan \left[\frac{\theta_{2}}{2}\right]\left(h_{-} h_{0}+\mathrm{x}\right)^{2.5} \\
& +\frac{8}{15} C_{d_{1}} \sqrt{2 g} \tan \left[\frac{\theta_{1}}{2}\right] h_{0}^{2.5} \\
& -\frac{8}{15} C_{d_{2}} \sqrt{2 g} \tan \left[\frac{\theta_{2}}{2}\right] x^{2.5}
\end{aligned}
$$

Where, $x$ is the height of the intersection triangle.

\section{Method-3}

It is the same as 'Method -1 ' but replacing the $C_{d}$ of the intersection triangle corresponding to the upper ' $V$ ' notch.

$$
\begin{aligned}
Q= & \frac{8}{15} C_{d_{2}} \sqrt{2 g} \tan \left[\frac{\theta_{2}}{2}\right]\left(h-h_{0}\right)^{2.5} \\
& +\frac{8}{15} C_{d_{1}} \sqrt{2 g} \tan \left[\frac{\theta_{1}}{2}\right] \cdot h^{2.5} \\
& -\frac{8}{15} C_{d 2} \sqrt{2 g} \tan \left[\frac{\theta_{1}}{2}\right]\left(h-h_{0}\right)^{2.5}
\end{aligned}
$$

\section{Method -4}

It is the same as 'Method -2' but replacing the $C^{d}$ of the intersection triangle corresponding to the lower ' $V$ ' notch.

$$
\begin{aligned}
Q= & \frac{8}{15} C_{d_{2}} \sqrt{2 g} \tan \left[\frac{\theta_{2}}{2}\right]\left(h-h_{0}+x\right)^{2.5} \\
& +\frac{8}{15} C_{d_{1}} \sqrt{2 g} \tan \left[\frac{\theta_{1}}{2}\right] h_{0}^{2.5} \\
& -\frac{8}{15} C_{d_{1}} \sqrt{2 g} \tan \left[\frac{\theta_{2}}{2}\right] x^{2.5}
\end{aligned}
$$

In Method-5 \& Method-6, it is considered that the intersection triangles do not contact with any solid boundaries and therefore, the $C_{d}$ values for the intersection triangles are eliminated.

\section{Experimental Details}

The experiments were carried out in the Hydraulics Laboratory of the Faculty of Engineering, University of Peradeniya. The experimental set-up mainly consists of a rectangular circulating open channel of $12 \mathrm{~m}$ long, $0.3 \mathrm{~m}$ wide and $0.3 \mathrm{~m}$ deep and a collecting tank at the downstream end of the channel. The compound sharp-crested weirs were built of GI plates and attached at the end of the open channel with the help of G-clamps and water sealant to prevent leakages.

The downstream collecting tank consists of two perforated plates to avoid the turbulence caused by the nappe from the elevated channel. A 


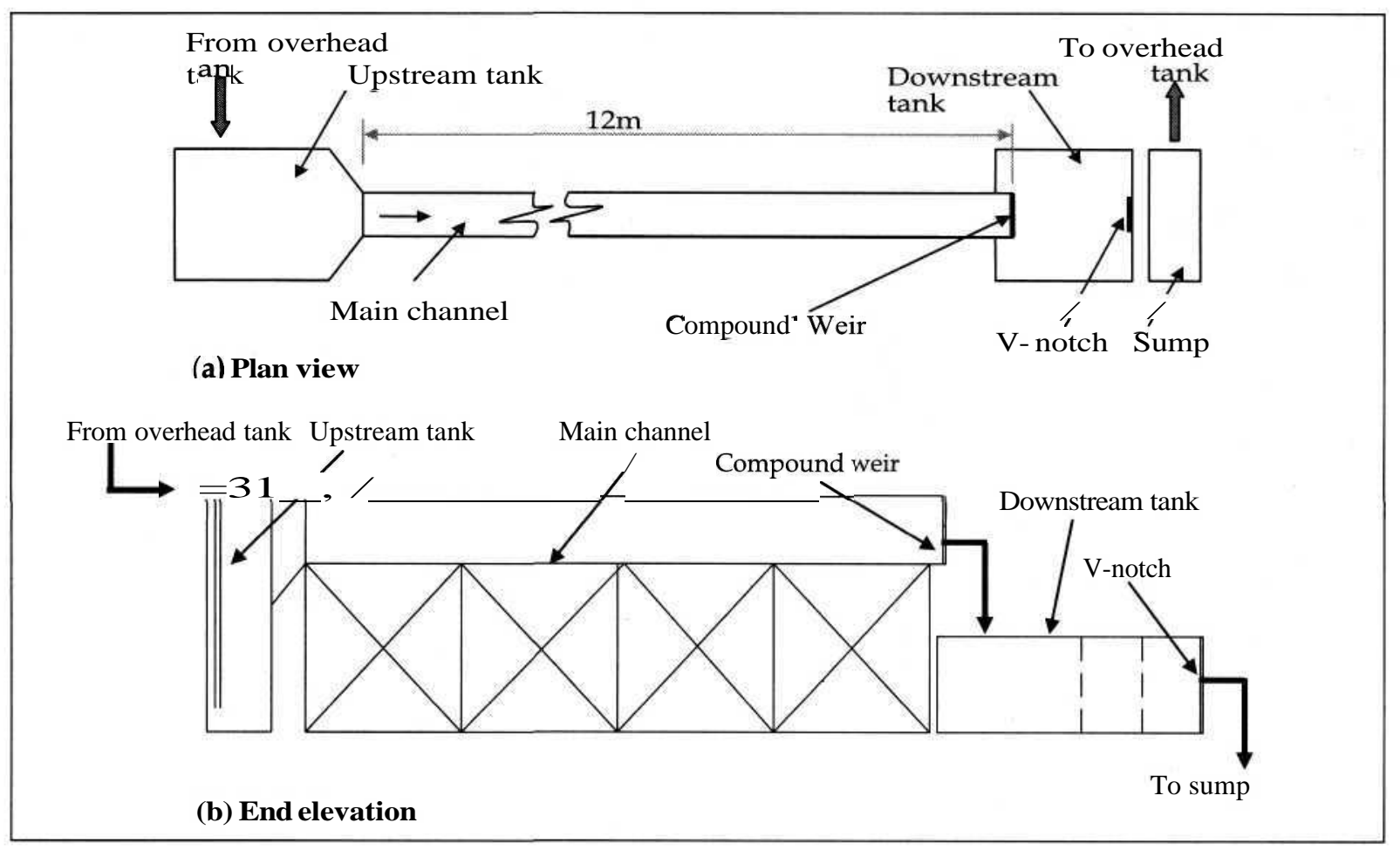

Figure 2. Schematic diagram of the experimental set-up (-notto scale-).

schematic diagram of the experimental set-up is shown in Figure 2.

Water was supplied to the main channel from an overhead tank at constant head and the flow was controlled by a gate valve. The flow was confirmed as steady uniform by the help of the backwater height measurements at subsequent intervals. The actual discharge through the channel was measured by means of the ' $V$ ' notch attached to the downstream collecting tank. For this purpose, initially it was calibrated accurately by using a volumetric method. The water depth was measured from a fixed height along the centre line of the main channel using a point gauge with an accuracy of $0.0508 \mathrm{~mm}(0.02$ inch).

Initially, several experimental runs were carried out with single ' $\mathrm{V}$ ' notches having $60^{\circ}, 90^{\circ}, 120^{\circ}$ $\& 150^{\circ}$ notch angles to find out their discharge coefficients. Due to the proximity of the walls of the approach channel, the contractions are not fully developed. So the notch is defined as a partially contracted, triangular thin-plate weir. As the flow conditions exceed the limitation prescribed for partially contracted flow in BSI (1965) and USBR (1997), the effect of the weir height $(p)$ on the discharge coefficients was checked by conducting the trials with different ' $b$ 'values for these single ' $V$ ' notches.

Altogether eight combinations of double ' $\mathrm{V}$ ' notches were tested by changing $\theta_{1}, \theta_{2}$ and lower ' $V$ ' notch height (see Table 1). Discharge in the channel was increased in steps of nearly $1 \mathrm{~L} / \mathrm{s}$ during experiments. Table 2 shows a summary of experimental data used for different test cases.

Table 1: Combinations of ' $V$ ' notches

\begin{tabular}{|c|c|c|c|}
\hline $\begin{array}{c}\text { Compound } \\
\text { weir type }\end{array}$ & $\begin{array}{c}\text { Height of } \\
\text { the lower } \\
\text { 'V' notch } \\
(h / \mathrm{cm})\end{array}$ & $\begin{array}{c}\text { Lower } \\
\text { notch } \\
\text { angle }\left(\theta_{1}\right)\end{array}$ & $\begin{array}{c}\text { Upper } \\
\text { notch } \\
\text { angle } \\
\left(\theta_{1}\right)\end{array}$ \\
\hline 1 & 15 & $60^{\circ}$ & $90^{\circ}$ \\
2 & 15 & $60^{\circ}$ & $120^{\circ}$ \\
3 & 15 & $60^{\circ}$ & $150^{\circ}$ \\
4 & 10 & $90^{\circ}$ & $120^{\circ}$ \\
5 & 10 & $90^{\circ}$ & $150^{\circ}$ \\
6 & 10 & $60^{\circ}$ & $90^{\circ}$ \\
7 & 10 & $60^{\circ}$ & $120^{\circ}$ \\
8 & 10 & $60^{\circ}$ & $150^{\circ}$ \\
\hline
\end{tabular}

Table 2: Summary of experimental data

\begin{tabular}{|l|l|}
\hline Parameter & Range \\
\hline Main channel discharge, (L/s) & $0.30-13.12$ \\
Upstream depth of flow, (m) & $0.09-0.23$ \\
Weir height, $p(\mathrm{~cm})$ & $2.5-10.0$ \\
\hline
\end{tabular}




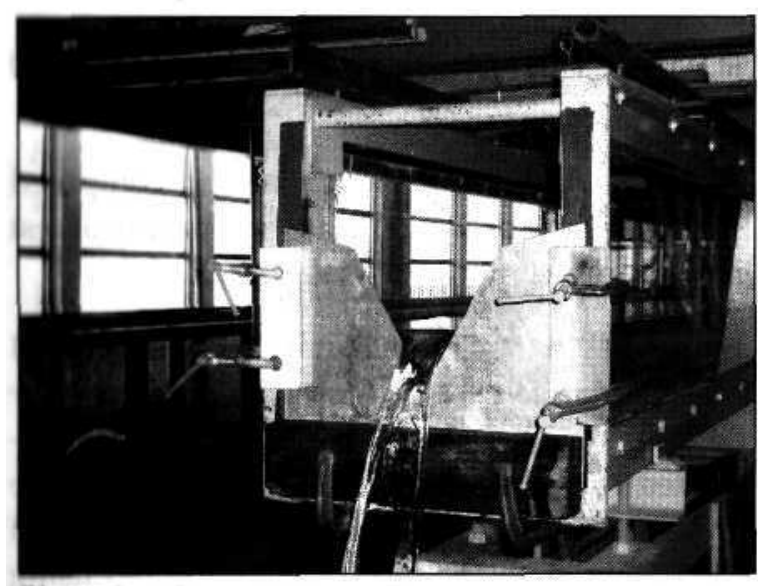

Figure 3 - The experimental set-up

\section{Data Analysis}

The analysis of experimental data is aimed at checking the continuity of flow over the compound weir, suitability of the equations proposed for discharge computations (Sec.3) and the accuracy of the proposed weir for discharge measurements. The ' $\mathrm{V}$ ' notch attached to the downstream collecting tank is calibrated precisely and $C_{d}$ is calculated as 0.627 . As stated earlier, the $C_{d}$ values for the single ' $\mathrm{V}$ ' notches are computed by changing the weir height $p$. The $C_{d}$ values for the $90^{\circ}$ ' $\mathrm{V}$ ' notch are given in Table 3 as a typical result.

Table 3: Cd values of $90^{\circ}$ ' $\mathbf{V}$ ' notch with changing weir heights

\begin{tabular}{|c|c|}
\hline Height of the weir $p /(\mathbf{c m})$ & $\boldsymbol{C}_{\boldsymbol{d}}$ \\
\hline 2.5 & 0.7061 \\
4.0 & 0.7005 \\
5.0 & 0.6943 \\
7.5 & 0.6942 \\
10.0 & 0.7035 \\
\hline
\end{tabular}

By considering the values given in Table 3, it can be noted that there is not much deviation of $C_{d}$ values for different values of $p$. Therefore, the effect of $p$ value on the discharge coefficient is rtssumed to be negligible within the experimental range covered in this study. Ilence, the $\mathrm{p}$ value is not taken as a variable for the remaining test cases. The $C_{d}$ values for single 'V notches are tabulated in Table 4.

Table 4: Cd values of single ' $V$ ' notches

\begin{tabular}{|c|c|}
\hline Notch Angle & Discharge Coefficient $\left(\boldsymbol{C}_{d}\right)$ \\
\hline $60^{\circ}$ & 0.654 \\
$90^{\circ}$ & 0.694 \\
$120^{\circ}$ & 0.663 \\
$150^{\circ}$ & 0.761 \\
\hline
\end{tabular}

\subsection{Continuity of flow}

The continuity of flow over the compound weirs for variation of head is checked using experimental data. As a typical result, the variation of measured discharge with head for compound weir types 6,7 and 8 is shown in Figure 4.

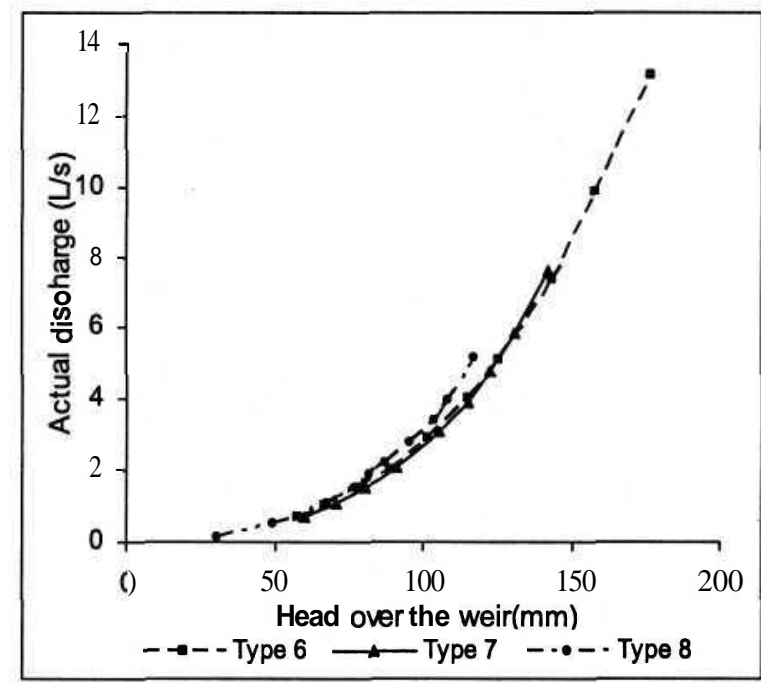

Figure 4 - Variation ofmeasured discharge with head for compound weir types 6, 7 and 8 .

As can be noted, there is no discontinuity of flow shown at the transition region of the two triangular notches. This is not the case with compound weirs having a rectangular notch with a $V$ notch at the centre, where the discharge versus head relationship is not continuous and as a result, when the head is near the transition region the flow measurements are not very accurate. Such difficulties could be overcome with the use of compound weirs having double ' $V$ ' notches as suggested during this study.

\subsection{Selection of best method}

Discharges over the compound sharp-crested weirs for all test cases are computed by using six different methods outlined in section 3 . The comparison between measured and computed discharges is shown in Figure 5.

It can be seen that the discharge computed by using methods 2, 4 and 6 have highly underestimated the discharge over the compound weirs, whereas methods 1,3 and 5 appear to be more suitable for estimating the discharge over the compound weir.

In order to compare the six different methods suggested in this study for estimating the 


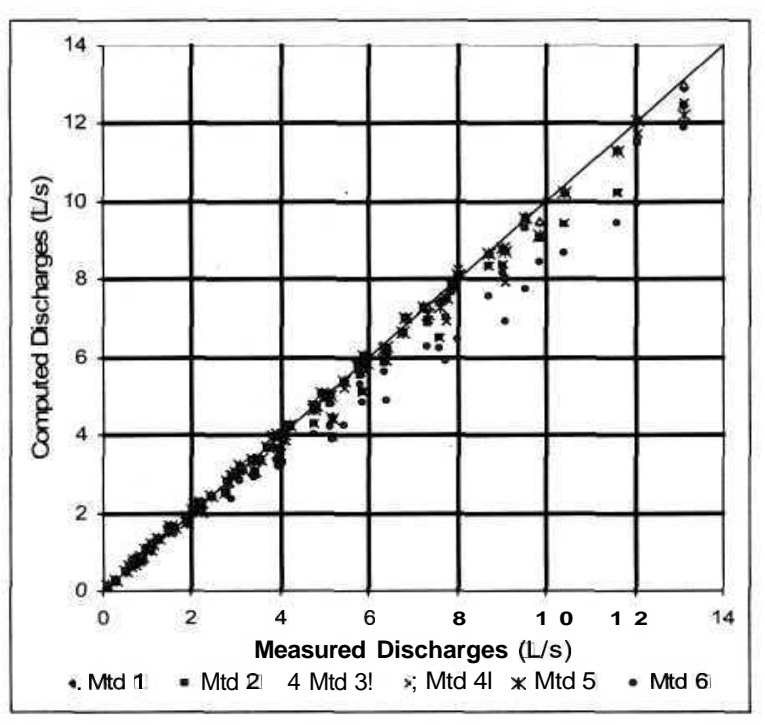

figure 5. Comparison between measured and computed discharges using six different methods.

discharge over the compound sharp-crested weir, the gradients obtained from the graphs of computed discharge versus actual discharge for each double ' $\mathrm{V}$ ' notch combinations are taken into consideration. The gradient reaches one when the method is more accurate. The variance of the gradients with one is calculated by using the Eq.(8).

$V=\frac{\sum(y-1)^{2}}{(n-1)}$

Where, $\mathrm{V}$ is the variance with 1 and $y$ is the gradient of the measured versus computed discharge graph for a specific method in each combination and $n$ is the number of test runs.

The average percentage error $(E)$ between the actual and computed discharges is also computed using Eq.(9).

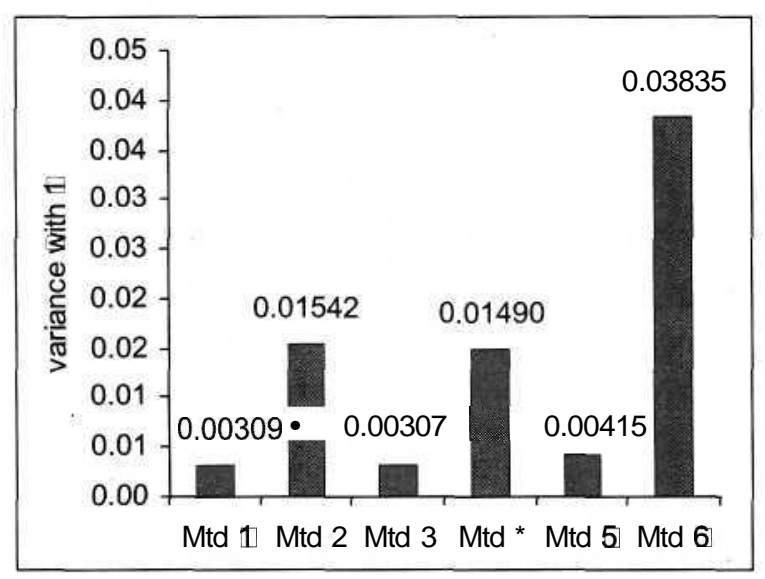

Figure 6. The variance of the gradients with methods of computing discharges
$E=\frac{100}{N} \sum_{i=1}^{N}\left|\frac{G_{a}-G_{c}}{G_{a}}\right|$

Where $G_{a}$ and $G_{c}$ are the actual and computed discharges, respectively. $\mathrm{N}$ is the number of test runs examined for a particular method.

According to the Figures 6 and 7, it can be noted that the method 3 is the most accurate one for computing discharge over compound sharpcrested weirs having double ' $\mathrm{V}$ 'notches. Figure 8 illustrates the comparison between measured discharges with the discharge computed using method 3 .

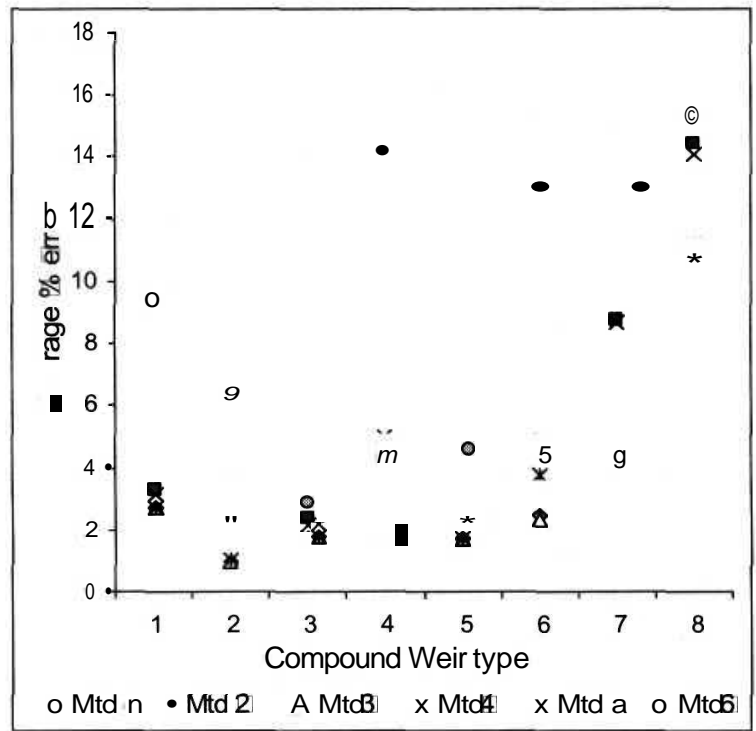

Figure 7. The average percentage errors between measured and computed discharges for different methods

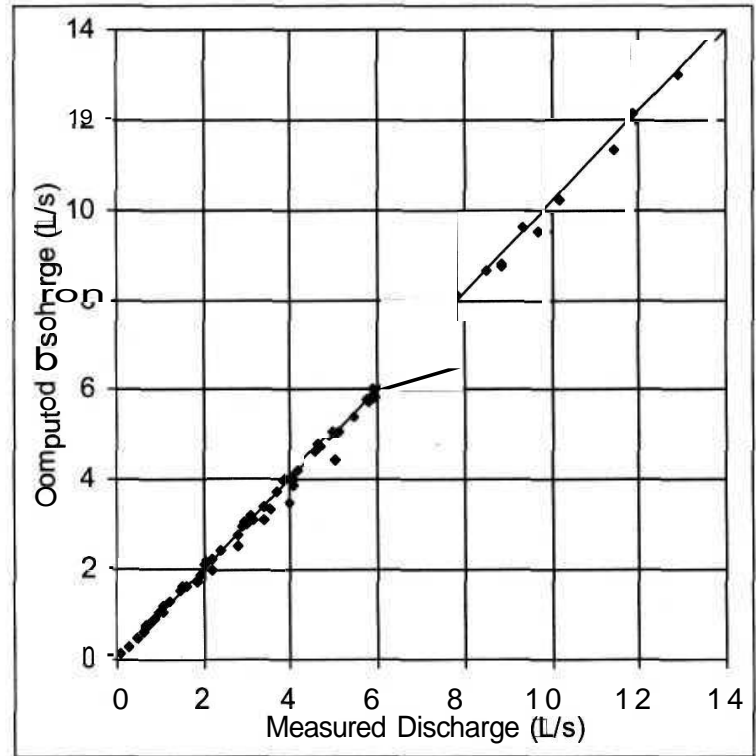

Figure 8. Comparison between measured and computed discharges using method-3 


\subsection{Accuracy of discharge measurements}

The accuracy of flow measurements using compound weirs, having a $60^{\circ}$ lower notch angle is compared with the accuracy of flow measurements by a single ' $\mathrm{V}$ ' notch of $60^{\circ}$. The percentage error that can be expected in flow measurements is computed according to Eq.(10) based on the accuracy of the point gauge used for head measurements which is $0.0508 \mathrm{~mm}$.

$\Delta Q(\%)=\frac{Q(h+0.0508)-Q(h-0.0508)}{2 Q(h)} \times 100$

Where, the function $Q(h)$ is taken according to the Method-3 and the variation of accuracy with head over the weir is shown in Figure 9. As can be seen in the figure, the accuracy of flow measurements using compound weirs with double ' $\mathrm{V}$ ' notches whose lower triangle is having a notch angle of $60^{\circ}$ is almost the same as the accuracy with a single ' $\mathrm{V}$ ' notch of $60^{\circ}$.

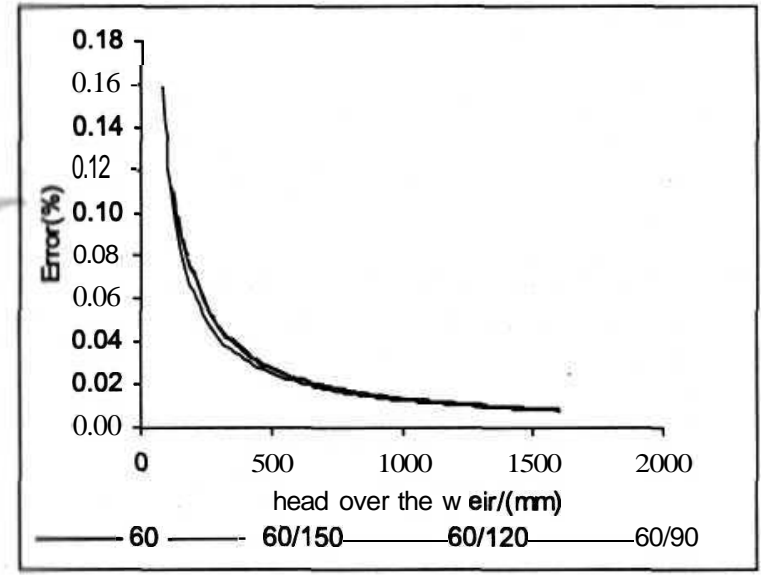

Figure 9. Variation of percentage error with head over the weir

\section{Summary and Conclusions}

A compound sharp-crested weir composed of two triangular parts with different notch angles has been analysed and experimentally validated to provide accurate measurements for a wide rage of flow without discontinuity. The most suitable method to estimate the flow over the double ' $V$ ' notch compound sharp-crested weir in partially contracted flow conditions, is found to be the procedure given in Method-3. Here, the intersection triangle is in the upper ' $V$ ' notch and the $\mathrm{C}_{\mathrm{d}}$ of that part is taken as the discharge coefficient of the upper ' $\mathrm{V}$ ' notch and the discharge can be computed using the Eq. 6 . This equation can be simplified in the form of;
$Q=\frac{8}{15} C_{d c} \sqrt{2 g} h^{2.5}$

Where,

$C_{d c}=C_{d 1} \tan \left[\frac{\theta_{1}}{2}\right]+C_{d 2}\left[\tan \left(\frac{\theta_{2}}{2}\right)-\tan \left(\frac{\theta_{1}}{2}\right)\right]\left(1-\frac{h_{0}}{h}\right)^{2.5} \cdots$

So, when there is a requirement to measure a wide range of flows accurately with reasonable sensitivity, the above compound sharp-crested weir can be selected due to its simplicity, easy maintenance and good flow measurement precision.

Figures 10, 11 and 12 illustrate the final discharge coefficients $\left(C_{d c}\right)$ for different heads above the weir for various combinations of ' $\mathrm{V}$ ' notches tested during this study. These curves can be used to obtain a correct discharge coefficient depending on the combination of ' $\mathrm{V}$ ' notches in sharp-crested compound weirs.

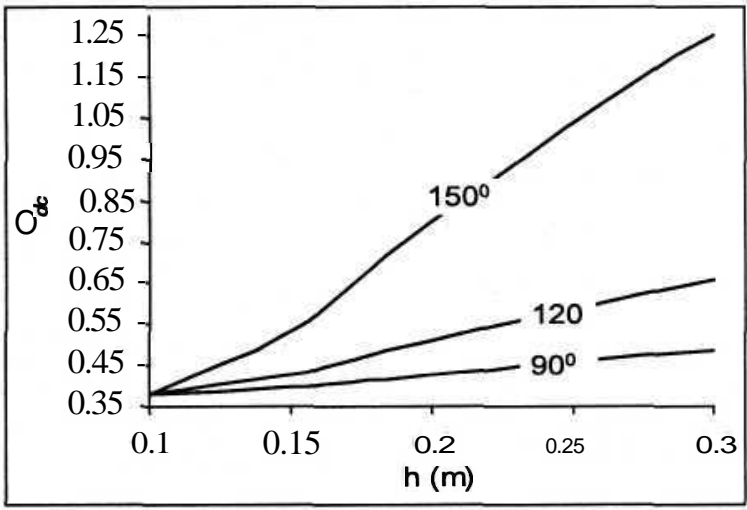

Figure 10. $\mathbf{C}_{\mathrm{d}}$ values for compound weirs having $60^{\circ}$ lower notch angle \& $10 \mathrm{~cm}$ lower weir height

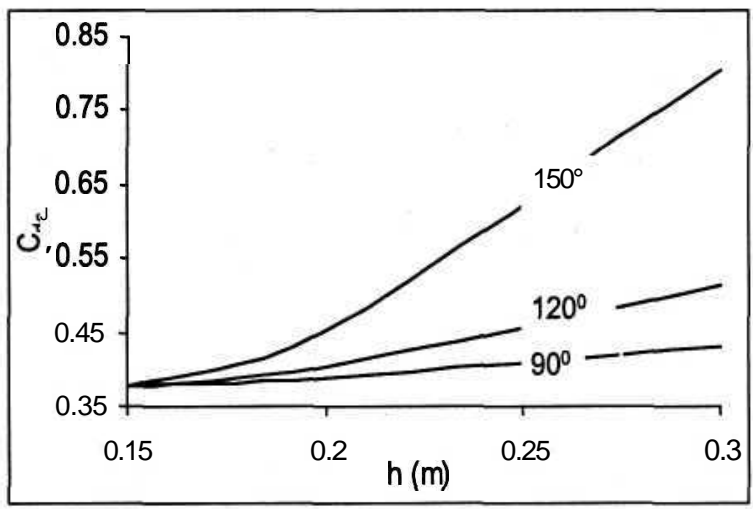

Figure 11. $\mathbf{C}_{\mathbf{d}}$ values for compound weirs having $60^{\circ}$ lower notch angle \& $15 \mathrm{~cm}$ lower weir height 


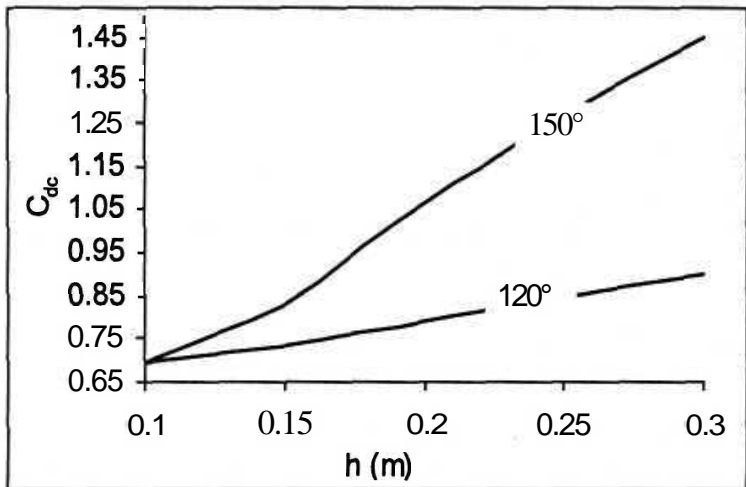

Figure 12. $\mathbf{C}_{\mathbf{d}}$ values for compound weirs having $\mathbf{9 0}^{\circ}$ lower notch angle \& $10 \mathrm{~cm}$ lower weir height

\section{References}

1. Abdel-Azim, M.N., Al-Brahim, A.M., and Alhamid, A.A (2002). "Combined free flow over weirs and below gates", Journal of Hydraulic Research, Vol.40(3), pp.359-365.

2. Aydin, I., Metin Ger, A., and Hincal, o. (2002) "Measurement of small discharges in open channels by slit weir", Journal of Hydraulic Engineering, Vol.128(2), pp.234-237.

3. Borghei, S.M., Jalili, M.R., and Ghodsian, M. (1999) "Discharge coefficient for sharp-crested side weir in subcritical flow", Journal of Hydraulic Engineering, Vol.125 (10), pp.10511056.

4. Bos, M.G. (1989) "Discharge measurement structures", International Institute for land Reclamation and Improvement (ILRI), publication 20, Wageningen, The Netherlands.
5. Brater, E.F., King, H.W., Lindell, J.E., and Wei, C.Y. (1996) "Handbook of Hydraulics", McgrawHill, New York.

6. British Standards Institution (BSI). (1965). "Thin plate weirs and venture flumes in methods of measurement of liquid flow in open channel", Part 4A, BSI 3680, London.

7. Chow, V.T. (1959) "Open channel Hydraulics", Mcgraw-Hill, New York.

8. Henderson, EM. (1966) "Open channel flow" Prentice-Hall, Englewood Cliffs, N.J.

9. Kindswater, C.E., and Carter, R.W. (1959) "Discharge characteristics of rectangular thin plate weirs", Trans. American Society of Civil Engineering, Vol. 124, pp.772-822.

10. Martinez, J., Reca, J., Morillas, M.T., and Lopez, J.G (2005) "Design and calibration of a compound sharp-crested weir", Journal of Hydraulic Engineering, Vol. 131, No. 2, pp.112116.

11. Swamee, P.K., qha, C.S.P., and Kumar, S. (1998) "Discharge equation for rectangular slots", Journal of Hydraulic Engineering, Vol. 124(9), pp.973-974.

12. LMNO Engineering Research and Software Ltd. (1999) "Focus on open channel flow measurement: V-notch weirs" Newsletter, Vol. 1, Athens, Ohio.

13. United States Department of the Interior, Bureau of Reclamation (USBR). (1997), Water measurement manual, 3rd Ed., Denver. 